\title{
Reproduction and Breast Cancer Risk
}

\author{
Volker Hanf ${ }^{a}$ Dorothea Hanf ${ }^{b}$ \\ ${ }^{a}$ Frauenklinik Nathanstift and Breast Cancer Centre Fürth, Germany \\ ${ }^{\mathrm{b}}$ Carl-Gustav-Carus Medical School, Technical University Dresden, Germany
}

\section{Keywords}

Breast cancer - Reproduction - Hormonal carcinogenesis . Transplacental carcinogenesis - Oral contraceptives .

Xenoestrogens - Infertility treatment .

Gestational diabetes mellitus - Pregnancy complications . Breast feeding

\section{Summary}

Reproduction is doubtlessly one of the main biological meanings of life. It is therefore not surprising that various aspects of reproduction impact on breast cancer risk. Various developmental levels may become targets of breast tumorigenesis. This review follows the chronologic sequence of events in the life of a female at risk, starting with the intrauterine development. Furthermore, the influence of both contraceptive measures and fertility treatment on breast cancer development is dealt with, as well as various pregnancy-associated factors, events, and perinatal outcomes. Finally, the contribution of breast feeding to a reduced breast cancer risk is discussed.

\section{Introduction}

Breast cancer is the most common malignant disease in women. A significant cause for concern are incidence rates which have been rising since at least 1935-1939. Overall, ageadjusted incidence rates rose by $25 \%$ from the early 1980 s to 1993 and an additional 15\% through 2001, then dropped by $18 \%$ until 2004 and finally edged upwards in 2006 [1]. It has been proposed that reproductive factors are amongst the most relevant contributors to personal risk, and that the approximated $1 \%$ annual incidence rise [2] is mainly due to reproductive factors.

\section{KARGER}

Fax +497614520714

\section{(c) 2014 S. Karger AG, Freiburg}

$1661-3791 / 14 / 0096-0398 \$ 39.50 / 0$
Since there are so many different aspects of reproduction to be considered, this review cannot deal with every aspect in detail but will focus on the most interesting perspectives. In order to propose an elucidating model of reproductive factors in the development of breast cancer, we decided to follow the chronologic sequence of events in the life of a female at risk with the following, admittedly somewhat arbitrary, stages:

i) The person at risk as a product of procreation (prenatal life)

ii) The pre-reproductive phase in life (preventing pregnancy, infertility treatment)

iii) Pregnancy and breast feeding as influencing factors

\section{The Person at Risk as a Product of Procreation (Prenatal Life)}

'I propose...' (the hypothesis)... 'that increased concentrations of estrogens in pregnancy (possibly with increased concentrations of other hormones in pregnancy) increase the probability of daughters getting breast cancer by creating a 'fertile soil' for subsequent cancer initiation' (Trichopoulos, 1990) [3]. Trichopoulos stated that factors which increase the risk of cancer during adult life might also increase the risk of cancer when they act in utero (e.g. ionizing radiation and diethylstilbestrol in human beings and other chemicals in animals). To him, the existing empirical data seemed compatible with the hypothesis that increased concentrations of estrogens in pregnancy (and might we add today: 'and other growthpromoting factors') increase the probability of future occurrence of breast cancer in daughters.

This early proposal by Trichopoulos is as thought-provoking and elucidating as ever: The concept explains that the development of breast cancer can start during prenatal life with a functional imprint on the developing breast tissue leading to increased susceptibility of the tissue to further hits, ultimately leading to breast cancer. It should however be kept in mind 
Table 1. Mean age at first birth in West Germany

\begin{tabular}{ll}
\hline Year & Maternal age at first birth, years \\
\hline 1965 & 24.9 \\
1970 & 24.3 \\
1985 & 26.2 \\
1995 & 28.2 \\
2010 & 30.2 \\
\hline
\end{tabular}

Source: $w w w . b p b . d e /$ nachschlagen/zahlen-undfakten/soziale-situation-in-deutschland/61556/ alter-der-muetter

that breast tissue does not achieve final differentiation before the first full-term pregnancy followed by a significant period of lactation. After this, the terminal ductulo-lobular unit reaches a finally differentiated state in which breast tissue has been experimentally shown to be much less vulnerable to induction of preneoplastic lesions [4, 5].

Accepting this concept, at least 2 new insights can be reached:

Firstly, a solid part of the historically proven rise in breast cancer incidence can be explained by the continuing postponement of first pregnancy to older age (table 1), which extends the vulnerable period of postnatal life, resulting in increased chances for initiating events to occur in the breast tissue $[6,7]$. What the newly opened door of 'social freezing' might lead to can now be anticipated. Beyond that, many women remain without any full-term pregnancy, exposing themselves to a lifelong threat of cancer induction.

Secondly, a possible avenue of prevention emerges: if a hormonally mimicked sham pregnancy can be induced, and a limited time of pseudo-lactation could be endured, childless women may be able to achieve the same reduced risk as young mothers [8]: the authors describe in their recent review the main changes in morphology and gene expression levels of the mammary gland of Sprague-Dawley rats exposed to known cancer-preventative conditions (pregnancy, human chorionic gonadotropin (hCG) and progesterone + estrogen). In addition, they postulate a protective mechanism induced by hCG that could reduce the cells' potential to be transformed by carcinogens.

Following the logical path of Trichopoulos' hypothesis, and searching for evidence that prenatal growth promotion might be associated with increased postnatal breast cancer risk, immediately several distinctive groups of growth modulators come to mind. To name just a few: hormonal (steroidal) influences (e.g. estrogens, progestins), growth factors (non-steroidal, e.g. insulin), and physical influences (e.g. heat (fever), ionizing radiation).

\section{Placental Steroids}

Only recently, it became possible to more precisely define steroid levels in umbilical cord blood [9]. It was shown that contrary to common belief levels of all estrogens (E1-E4) ex-

Table 2. Daughters' risk with various prenatal conditions

\begin{tabular}{llc}
\hline Item & Effect & Ref. \\
\hline Twin pregnancy & $\begin{array}{l}\text { divergent results, slightly } \\
\text { elevated risk }\end{array}$ & {$[10]$} \\
Twin pregnancy & $\begin{array}{l}\text { decreased risk } \\
\text { decreased risk }\end{array}$ & {$[9]$} \\
Preeclamptic pregnancy & $\begin{array}{l}\text { no elevated risk } \\
\text { Preterm delivery }\end{array}$ & {$[19]$} \\
Increasing birth weight & consistently elevated risk & {$[10]$} \\
& elevated risk & {$[16]$} \\
Increasing birth length & $\begin{array}{l}\text { decreased risk, especially } \\
\text { Ever maternal diabetes }\end{array}$ & {$[50]$} \\
$\quad$ mellitus & $\begin{array}{l}\text { pre-menopausal } \\
\text { divergent results, slightly }\end{array}$ & {$[10]$} \\
Maternal age & elevated risk & \\
Paternal age & case control study: trend & {$[52]$} \\
for increased risk & no association & {$[53]$} \\
Maternal pre-pregnancy body & & \\
$\quad$ mass index and weight gain & &
\end{tabular}

amined were reduced in twin as compared to singleton pregnancies. Further, E1 and E2 concentrations were not associated with preeclampsia in the current pregnancy, but E3 and E4 concentrations were lower in pregnancies complicated by preeclampsia.

Xue et al. [10] investigating the preconditioning relevance of prenatal estrogen exposure as hypothesized by Trichopoulos performed a systematic review in 2007 and noted a decreased risk of breast cancer for maternal preeclampsia and eclampsia (0.48 (0.30-0.78)) and twin pregnancy (0.93 (0.871.00)). Park et al. [11] however found in their review somewhat divergent and in summary slightly contradictory trends for twin pregnancies. Table 2 summarizes prenatal conditions and their effects on later breast cancer risk.

\section{Exposure to Estrogens or Agents with Estrogen-Like Activity (Xenoestrogens)}

In the 1950ies and 1960ies, when pregnant women at risk of miscarriage were treated with the synthetic estrogen diethylstilbestrol (DES), their daughters were imprinted to develop rare clear cell adenocarcinoma of the vagina. This disaster was the first proven example of transplacental carcinogenesis in humans. Since then, it is a matter of debate whether breast cancer risk in DES daughters is consistently elevated above background level. In a very recent review, Hilakivi-Clarke [12] addressed the mechanisms that may explain why DES daughters have a 2 times higher breast cancer risk than women who were not exposed to it. The mechanisms most likely involve epigenetic alterations, such as increased DNA methylation and modifications in histones and microRNA expression. It appears that these alterations target genes that regulate stem cells and prevent differentiation of their daughter cells. The 
author reports that recent findings in a preclinical model suggest that not only women exposed to DES in utero are at increased risk of developing breast cancer, but this risk may extend to their daughters and granddaughters as well.

As with thalidomide, the catastrophe of DES could have been foreseen if animal data would have been taken into account or had been collected in the first place. Today, it has been recognized that in rats prenatal exposure to DES results in increased mammary cancer incidence during adulthood when these animals are challenged with the chemical carcinogen dimethylbenzanthracene (DMBA) in puberty [13]. Soto et al. [14] have repeatedly warned that animal data suggest that bisphenol A, a widespread environmental man-made chemical contaminant with xenoestrogeneic activity, predisposes rodent mammary glands to the development of breast cancer when exposure takes place in the womb or through lactation. Previously, in analytical work, we repeatedly detected xenoestrogeneic activity in surface water in Germany $[15,16]$.

\section{Growth Factors (Non-Steroidal, e.g. Insulin)}

Troisi et al. [17] carried out a population-based study to correlate perinatal characteristics of girls with their later life risk of developing breast cancer. Breast cancer risk rose by $7 \%$ with every $500 \mathrm{~g}$ (roughly 1 standard deviation (SD)) increase in birth weight and 7\% for every 1 SD increase in birth length. The association with birth length was attenuated after adjustment for birth weight, while the increase in risk with birth weight remained after adjustment for birth length. Risk was not associated with maternal education, gestational duration, delivery type or birth order, or with several pregnancy complications including preeclampsia.

One of the driving mediators of fetal growth is without any doubt insulin. Disturbed glucose tolerance is frequently encountered in pregnant women and is about to become yet more frequent as maternal age at first pregnancy and body mass index are continually rising. Gestational diabetes mellitus (GDM), just like various forms of disturbed glucose tolerance including type 2 diabetes, is accompanied by hyperinsulinemia. Type 2 diabetes is a risk factor for breast cancer in postnatal life [18]. Therefore, it is justified to suspect that hyperinsulinemia could also be a risk factor for daughters from GDM pregnancies. However, no literature clarifying this notion could be found.

It is worth mentioning that the determination of placental growth factor (PlGF) (and soluble vascular endothelial growth factor receptor sFlt-1) has recently become a clinical method of estimating a woman's risk for preeclampsia. While sFlt-1 inhibits vascular growth, PlGF promotes it. In preeclampsia, sFlt-1 is increased in relation to PlGF. What are the implications for breast cancer risk? PlGF is produced by malignant tissue enhancing breast cancer cell mobility [19]. Although the available data are somewhat conflicting [17] (Table 2), as mentioned above in the context of reduced placental steroids, there is evidence for a reduced risk for daugh- ters born from preeclamptic pregnancies. Ekbom et al. [20] found a markedly and significantly reduced risk for breast cancer in women whose mothers had 'pregnancy toxemia', i.e. preeclampsia. Additionally, a meta-analysis has shown that among all women, preeclampsia-born offspring had a $52 \%$ lower risk of breast cancer [10].

\section{Physical Influences}

Ionizing radiation administered prenatally can readily induce initiation just as it can postnatally, particularly in childhood. The atomic bomb disasters in Japan prove that young girls are at particular risk: the 'in-utero cohort' is composed of about 3,300 individuals who were in their mother's womb at the time of the bombings. The cohort was followed up for mortality and cancer incidence, and a subset is being clinically monitored with biennial clinical examinations [21]. A recent report compared the risk estimates for those exposed in utero and during childhood with respect to the incidence of solid cancer at ages $12-55$ years. Although there was a statistically significant dose dependence for the in-utero group, the cancer risk was nominally smaller overall than in the childhood-exposure group. The authors concluded that in-utero exposure does not appear to confer greater adult cancer risk than childhood exposure, but further follow-up to older ages was recommended. Goto et al. [22] investigated cancer mortality among atomic bomb survivors exposed as children. Standardized mortality ratios were significantly higher for exposed girls for all cancers; however, a dose distribution for various types was found. For breast cancer, exposure to higher doses conferred a significantly elevated risk. Evidently, ionizing radiation can prime for cancer in the unborn.

\section{The Pre-Reproductive Phase in Life (Preventing Pregnancy)}

As indicated above, age at first full-term pregnancy is a powerful denominator of future breast cancer risk [7] as it determines the length of time the undifferentiated breast tissue remains particularly vulnerable. However, instead of securing breast cancer protection for future life, most young women are trying to prevent an early pregnancy. While non-hormonal methods would not as such be under suspicion of modulating breast cancer risk (aside from the precarious delay of breast tissue differentiation), hormonal interventions could cause such a risk modulation.

A differential approach appears appropriate here: while modern oral contraceptives (OC) expose breast tissue to lower estrogen peaks than would be encountered in normally cycling women, this could in principle be either beneficial or detrimental: i) detrimental in the way that a pseudopregnant state with high estrogen and progesterone levels is avoided, depriving hormonal contraception of the inherent option of inducing final differentiation and thereby lowering future vul- 
nerability to breast cancer; ii) beneficial in the way that breast epithelial proliferation is without question driven by estrogens, and lower estrogen peaks of modern OC could in principle reduce risk.

Epidemiological studies show that 'taking the pill' does modify a woman's risk of developing breast cancer. Compared with never use, ever use of OC is significantly associated with a decrease in colorectal and endometrial cancers and an increase in breast cancer. Although the elevation in breast cancer risk was small, the relatively high incidence of breast cancer and the very high number of exposed women mean that OC may contribute to a substantial number of cases [23]. Beaber et al. [24] presented data from a very recent nested case-control study using ascertained OC use information from electronic pharmacy records. Recent OC use was associated with an increased breast cancer risk (odds ratio (OR) 1.5) relative to never or former OC use. The association was stronger for estrogen receptor-positive disease, although not statistically significant. Recent OC use involving highdose estrogen (OR 2.7), ethynodiol diacetate (OR 2.6), or triphasic dosing with an average of $0.75 \mathrm{mg}$ of norethindrone (OR 3.1) was associated with particularly elevated risks, whereas other OC types including low-dose estrogen were not (OR 1.0; 95\% confidence interval (CI) 0.6-1.7).

These data show that it appears prudent to look with caution on the various synthetic progestins as part of modern OC. Little is known about the differential ability of these agents to drive breast cancer risk. Preclinical experimental [25], and epidemiological and experimental data of the Womens' Health Initiative (WHI) study suggest that in postmenopausal hormone therapy it is the progestins that pose the pharmacological risk [26]. In humans, these differential progestin effect data are only sparsely available. An in depth review of animal and preclinical data is beyond the scope of this paper.

Finally, the timing of the onset of OC use is of clinical importance: a database review of 1,010 breast cancer patients produced evidence of a linear trend between age at OC start and age at breast cancer diagnosis. Women who started using the OC aged 18 years or younger were on average 4 years younger at the time of breast cancer diagnosis than women who started using the OC over the age of 30 years [27].

If an unwanted pregnancy occurs, it may result in spontaneous miscarriage or an induced abortion might be resorted to. Beral et al. [28] carried out a collaborative reanalysis of data from 53 epidemiological studies including 83,000 women with breast cancer to study the effects of previous miscarriages/ abortions. They concluded that pregnancies that end by spontaneous or induced abortion do not increase a woman's risk of developing breast cancer. In Chinese women, essentially the same was found, specifically for induced abortion [29].

In some women discontinuation of contraceptive measures does not result in the then desired conception, and for various reasons assisted reproductive interventions become necessary. The reasons why reproductive medical measures have to be applied might in themselves modulate future breast cancer risk in the affected individuals:

Hormonally 'healthy' women that have to resort to assisted reproductive therapy for andrologic or purely mechanical (e.g. after tubal ligation) reasons might have a different susceptibility to induction of breast cancer than women with endocrine problems requiring medical intervention.

Women with longstanding hypoestrogenic dysfunctions (e.g. hypothalamic ovarian failure) should experience a reduced risk similar to women who were ovarectomized at a young age.

Women with impaired intraovarian regulation (e.g. polycystic ovarian syndrome PCOS) with excess of free circulating androgens and constantly slightly elevated levels of estradiol and anovulation have to be viewed separately. Barry et al. [30] performed a systematic review of studies of women with and without PCOS. Their data suggested that women of all ages with PCOS are at an increased risk of endometrial cancer, but the risk of ovarian and breast cancer was not significantly increased overall. However, the available evidence was classified as 'far from robust'.

Women with repeated ovarian stimulation with antiestrogens (clomiphene citrate) or urinary or recombinant gonadotropins are again a different risk group. Zreik et al. [31] reviewed the literature and found that the risk of breast cancer was not significantly associated with fertility drug treatment. Brinton et al. [32] conducted an extended follow-up among a cohort of 12,193 US women evaluated for infertility between 1965 and 1988. During 30 median years of follow-up, 749 breast cancers were observed. Ever use of clomiphene citrate among $38.1 \%$ of patients was not associated with risk (hazard ratio $(\mathrm{HR})=1.05 ; 95 \%$ CI 0.90-1.22) compared to never use. However, somewhat higher risks were seen for patients who received multiple cycles, with the risk for confirmed invasive cancers being significantly elevated ( $\mathrm{HR}=1.69$; 95\% CI $1.17-$ 2.46). This risk remained relatively unchanged after adjustment for causes of infertility and multiple breast cancer predictors. Gonadotropins, used by $9.6 \%$ of patients mainly in conjunction with clomiphene, showed inconsistent associations with risk, although a significant relationship of use with invasive cancers was seen among women who remained nulligravid (HR 1.98). The authors felt that this increased breast cancer risk among nulligravid women associated with gonadotropins most likely reflected an effect of underlying causes of infertility, and that additional evaluation of long-term fertility drug effects on breast cancer was warranted.

Along the same lines are the findings of Sergentanis et al. [33] who systematically reviewed the literature and concluded that controlled ovarian hyperstimulation for in vitro fertilization does not seem to confer an increased breast cancer risk. However, before definite conclusions concerning the safety of this treatment can be drawn, the authors would like to see longer follow-up periods, appropriate controls and comparisons, and adjustment for various confounders. 


\section{Pregnancy and Breast Feeding as Influencing Factors}

\section{Pregnancy}

Conception opens up a new chapter in our considerations on reproductive factors in the development of breast cancer. A number of influences have already been mentioned, albeit from a different perspective: that of the developing fetus. Now the focus is on the pregnant mother herself. The situation of an unsuccessful pregnancy resulting in miscarriage/ abortion has already been dealt with.

It has been known for a long time that the age at first pregnancy has a very profound influence on future breast cancer risk. MacMahon et al. [6] deduced that the reduced risk of breast cancer in women having their first child at an early age explains the previously observed inverse relationship between total parity and breast cancer risk, since women having their first birth early tend to become ultimately of high parity. Recently, it was reconfirmed that age at first birth also has an impact on molecular subtypes if breast cancer arises: Horn et al. [34] found that older age at first birth and low parity were associated with increased risk for luminal breast cancer subtypes.

Further conceivable influencing factors could be multifetal pregnancies that expose the mother to high amounts of placental growth factors and hormones different from those in singleton pregnancies, GDM accompanied by hyperinsulinemia, and preeclampsia with reduced placental mass and function. A possible consequence might be fetal retardation and/ or preterm delivery. Finally, timing of delivery, postterm delivery, and mode of delivery are also conceivable factors. An overview of the current knowledge is given in table 3. To go into further details about all these aspects would go beyond the scope of this review.

To clarify the conflicting data from individual studies on maternal breast cancer risk and preeclamsia or pregnancy-induced hypertension, Kim et al. [35] performed a meta-analysis and found non-significantly reduced relative risks (RR) for both preeclamsia (RR 0.86) and pregnancy-induced hypertension (RR 0.83).

Equally, the available data on the impact of having twins was conflicting so that a meta-analysis was necessary. Kim et al. [36] detected an RR of $0.94(p=0.127)$ suggesting that twin pregnancy does not significantly decrease the maternal risk of breast cancer.

It would appear plausible that GDM could pose a cancer risk in affected mothers, and indeed there is a strong association with pancreatic cancer but not with breast cancer. Tong et al. [37] reviewed a total of 9 articles documenting 5 cohort and 4 case-control studies comprising 10,630 cancer cases and 14,608 women with a history of GDM. Taken together, the pooled OR between GDM and breast cancer risk was 1.01 (0.87-1.17). These results should however be interpreted with caution because of certain methodological flaws.
Table 3. Maternal breast cancer risk in association with own obstetric history

\begin{tabular}{llr}
\hline Item & Effect & Ref. \\
\hline Increasing age at first pregnancy & $\begin{array}{l}\text { linearly increasing risk } \\
\text { Parity }\end{array}$ & {$[6]$} \\
Abortions & no elevated risk & {$[55]$} \\
Twin pregnancy & no significantly decreased & {$[35]$} \\
& risk & \\
At first multifetal pregnancy & slightly elevated risk & {$[37]$} \\
Gestational diabetes mellitus & no elevated risk & {$[36]$} \\
Nausea/vomiting & decreased risk & {$[56]$} \\
Preeclampsia & non-significantly reduced & {$[34]$} \\
& risk & \\
Pregnancy-induced & non-significantly reduced & {$[34]$} \\
$\quad$ hypertension & risk & \\
Delivering small for date baby & non-significantly reduced & {$[48]$} \\
& risk & \\
Extreme premature delivery & significantly elevated risk & {$[37]$} \\
$\quad(<32$ weeks $)$ & & \\
Smoking during first pregnancy & significantly elevated risk & {$[47]$} \\
\hline
\end{tabular}

Innes et al. [38] hypothesized that first pregnancy would be likely to have a significant impact on a woman's BC risk, and examined first pregnancy characteristics in a large New York cohort. Extreme prematurity ( $<32$ weeks gestational age) was associated with elevated maternal breast cancer risk (adjusted OR 2.1; 95\% CI 1.2-3.9), as were abruptio placentae (OR = 1.8 ) and multifetal gestation (OR 1.8). Preeclampsia was associated with a marked reduction in breast cancer risk among women who bore their first child after age 30 (OR 0.3) and in the first 3 years after delivery (OR 0.2).

No data could be retrieved on the association of breast cancer risk and postmaturity or mode of delivery including caesarian section. It should be kept in mind that all these imponderabilities in pregnancy might be acting as modulators of the preexisting individual breast cancer risk or could be in themselves mere indicators of underlying processes that are accompanied by an increased or lowered likelihood to develop breast cancer.

\section{Breast Feeding}

After pregnancy, an extended period of breast feeding contributes to the functional ripening of the glandular tissue. The duration of breast feeding within certain limits is believed to have an influence on breast cancer risk. In order to unravel the impact of breast feeding on breast cancer risk (reduction) within the complex topic of childbearing, the Collaborative Group on Hormonal Factors in Breast Cancer [39] retrieved individual data from 47 epidemiological studies in 30 countries that included information on breast feeding patterns and other aspects of childbearing for 50,302 women with invasive breast cancer and 96,973 controls. The RR for breast cancer decreased by $4.3 \%$ ( $<<0.0001)$ for every 12 months of breast feeding in addition to a decrease of $7.0 \%(\mathrm{p}<0.0001)$ for each 
birth. The authors estimated that the cumulative incidence of breast cancer in developed countries would be reduced by more than half, from 6.3 to 2.7 per 100 women by age 70 , if women had the average number of births and lifetime duration of breast feeding that had been prevalent in developing countries until recently. Breast feeding could account for almost two-thirds of this estimated reduction in breast cancer incidence. A recent workshop on postpartum remodeling, lactation, and breast cancer risk held by the National Cancer Institute stated that breast feeding may provide greater protection against triple-negative, basal-like, and BRCA1 mutationassociated breast cancer, suggesting particular protection against aggressive types of breast cancer [40].

Within this context, it should be noted that breast feeding has positive effects on maternal breast cancer risk beyond mere terminal differentiation of the glandular tissue: Exclusive breast feeding suppresses hypothalamic activity leading to hypogonadotropic hypoestrogenism through anovulation. This dormant endocrine state in itself is associated with decreased breast cancer risk. While hypoestrogenicity may be seen as a direct influence of breast feeding on breast cancer risk, the following indirect influences also play a role.

\section{Diabetes Mellitus}

Jäger et al. [41] extensively investigated the interrelationship between breast feeding and a mother's later risk of developing type 2 diabetes. The HR for each additional 6 months of breast feeding was 0.73 . A meta-analysis of 3 previous prospective studies and their own study revealed an inverse association between breast feeding duration and risk of diabetes. Type 2 diabetes mellitus, again, is a risk factor for breast cancer. Data reported by Onitilo et al. [42] support the notion that hyperinsulinemia, rather than hyperglycemia, as a major diabetes-related factor is associated with increased risk of breast cancer.

\section{RANKL Pathway Activation}

On the other hand, extensive breast feeding can lead to skeletal demineralization if calcium is taken up insufficiently to replenish internal stores. Such a deficit is accompanied by activation of the RANKL pathway. Experimental results by Xiong et al. [43] demonstrate that RANKL produced by osteocytes contributes to the increased bone resorption and bone loss caused by secondary hyperparathyroidism. RANKL pathway activation has been found to play a role in the risk modulation for postmenopausal breast cancer [44]. In order to minimize osteoporosis and its many unwanted sequelae, it is therefore advisable to secure a sufficient supply of calcium and vitamin D3 (sun exposure).

\section{Depletion of Xenoestrogen Stores}

The role of persistent organo-halogen compounds with xenoestrogeneic activity stored in adipose tissue for breast cancer development has been a matter of debate [45]. Once taken up, mainly via the oral route, it is virtually impossible to get rid of these persistent hormonally active agents (HAA), except via breast feeding: since adipose tissue is broken down in order to provide the basis for fatty acids and fat droplets in breast milk, mothers transfer significant amounts of HAA unto their infants [46]. Whether this decontamination process contributes to a reduced breast cancer risk is unknown and a matter of speculation. On the other hand, it could be hypothesized that this transfer of persistent HAA unto the child could possibly pose a risk for, in this context, breast cancer in the nursed child. However, nursing as a main source of infantile energy uptake has undisputed advantages, e.g. a lowered risk of later diabetes mellitus which in itself is a risk factor for breast cancer, or the prevention of obesity in later life as compared with bottle-fed children. Here, too, obesity as a risk factor for breast cancer (mortality) is avoided or ameliorated. It is, however, in this very complicated interplay of divergent influences extremely difficult to detect a truly existing effect: Wise et al. [47, 48] were unable to show an influence of being breast-fed as a baby on later breast cancer risk.

\section{Summary}

Reproduction is an important functional complex in our lives, hence it comes as no surprise that reproductive factors play a role in many other concepts such as the development of breast cancer as the most common malignant disease in women. Some factors could at least theoretically be incorporated into a risk-minimizing lifestyle while others are absolutely beyond the control of the individual at risk. What can be recommended is care when selecting $\mathrm{OC}$ with respect to the progestins involved and possibly a critical appraisal of the indication in young women, careful dietary advice in pregnancy to avoid GDM, and exclusive breast feeding for the recommended amount of time. In this way, mother and child will both benefit.

\section{Disclosure Statement}

With respect to this particular work, the authors have no conflicts of interest to declare. 


\section{References}

1 Glass AG, Lacey JV Jr, Carreon JD, Hoover RN: Breast cancer incidence, 1980-2006: combined roles of menopausal hormone therapy, screening mammography, and estrogen receptor status. J Natl Cancer Inst 2007;99:1152-1161.

$\checkmark 2$ Miller BA, Feuer EJ, Hankey BF: Recent incidence trends for breast cancer in women and the relevance of early detection: an update. CA Cancer J Clin 1993;43:27-41.

$\checkmark 3$ Trichopoulos D: Hypothesis: does breast cancer originate in utero? Lancet 1990;335:939-940.

4 Lamartiniere CA, Cotroneo MS, Fritz WA, Wang J, Mentor-Marcel R, Elgavish A: Genistein chemoprevention: timing and mechanisms of action in murine mammary and prostate. J Nutr 2002;132: 552S-558S.

$\checkmark 5$ Whitsett TG Jr, Lamartiniere CA: Genistein and resveratrol: mammary cancer chemoprevention and mechanisms of action in the rat. Expert Rev Anticancer Ther 2006;6:1699-1706.

6 MacMahon B, Cole P, Lin TM, Lowe CR, Mirra AP, Ravnihar B, Salber EJ, Valaoras VG, Yuasa S: Age at first birth and breast cancer risk. Bull World Health Organ 1970;43:209-221.

7 Hunt SC, Williams RR, Skolnick MH, Lyon JL, Smart CR: Breast cancer and reproductive history from genealogical data. J Natl Cancer Inst 1980;64: 1047-1053.

8 Santucci-Pereira J, George C, Armiss D, Russo IH, Vanegas JE, Sheriff F, de Cicco RL, Su Y, Russo PA, Bidinotto LT, Russo J: Mimicking pregnancy as a strategy for breast cancer prevention. Breast Cancer Manag 2013;2:283-294.

9 Hickey M, Hart R, Keelan JA: The relationship between umbilical cord estrogens and perinatal characteristics. Cancer Epidemiol Biomarkers Prev 2014;23:946-952.

10 Xue F, Michels KB: Intrauterine factors and risk of breast cancer: a systematic review and meta-analysis of current evidence. Lancet Oncol 2007;8:10881100.

11 Park SK, Kang D, McGlynn KA, Garcia-Closas M, Kim Y, Yoo KY, Brinton LA: Intrauterine environments and breast cancer risk: meta-analysis and systematic review. Breast Cancer Res 2008;10:R8.

12 Hilakivi-Clarke L: Maternal exposure to diethylstilbestrol during pregnancy and increased breast cancer risk in daughters. Breast Cancer Res 2014; 16:208.

13 Boylan ES, Calhoon RE: Transplacental action of diethylstilbestrol on mammary carcinogenesis in female rats given one or two doses of 7,12-dimethylbenz(a) anthracene. Cancer Res 1983:43:4879-4884.

14 Soto AM, Brisken C, Schaeberle C, Sonnenschein C: Does cancer start in the womb? Altered mammary gland development and predisposition to breast cancer due to in utero exposure to endocrine disruptors. J Mammary Gland Biol Neoplasia 2013;18:199-208.

15 Körner W, Hanf V, Schuller W, Kempter C, Metzger J, Hagenmaier H: Development of a sensitive E-screen assay for quantitative analysis of estrogenic activity in municipal sewage plant effluents. Sci Total Environ 1999;225:33-48.

16 Henneberg A, Bender K, Blaha L, Giebner S, Kuch B, Kohler HR, Maier D, Oehlmann J, Richter D, Scheurer M, Schulte-Oehlmann U, Sieratowicz A, Ziebart S, Triebskorn R: Are in vitro methods for the detection of endocrine potentials in the aquatic environment predictive for in vivo effects? Outcomes of the Projects SchussenAktiv and SchussenAktivplus in the Lake Constance Area, Germany. PloS One 2014;9:e98307.
7 Troisi R, Grotmol T, Jacobsen J, Tretli S, Toft-Sorensen H, Gissler M, Kaaja R, Potischman N, Ekbom A, R NH, Stephansson O: Perinatal characteristics and breast cancer risk in daughters: a Scandinavian population-based study. J Dev Orig Health Dis 2013;4:35-41.

18 Hardefeldt PJ, Edirimanne S, Eslick GD: Diabetes increases the risk of breast cancer: a meta-analysis. Endocr Relat Cancer 2012;19:793-803.

19 Taylor AP, Leon E, Goldenberg DM: Placental growth factor (PIGF) enhances breast cancer cell motility by mobilising ERK1/2 phosphorylation and cytoskeletal rearrangement. Br J Cancer 2010; 103:82-89.

20 Ekbom A, Hsieh CC, Lipworth L, Adami HQ, Trichopoulos D: Intrauterine environment and breast cancer risk in women: a population-based study. J Natl Cancer Inst 1997;89:71-76.

21 Douple EB, Mabuchi K, Cullings HM, Preston DL, Kodama K, Shimizu Y, Fujiwara S, Shore RE: Long-term radiation-related health effects in a unique human population: lessons learned from the atomic bomb survivors of Hiroshima and Nagasaki. Disaster Med Public Health Prep 2011; 5(suppl 1):S122-133.

22 Goto H, Watanabe T, Miyao M, Fukuda H, Sato Y, Oshida Y: Cancer mortality among atomic bomb survivors exposed as children. Environ Health Prev Med 2012;17:228-234.

23 Gierisch JM, Coeytaux RR, Urrutia RP, Havrilesky LJ, Moorman PG, Lowery WJ, Dinan M, McBroom AJ, Hasselblad V, Sanders GD, Myers ER: Oral contraceptive use and risk of breast, cervical, colorectal, and endometrial cancers: a systematic review. Cancer Epidemiol Biomarkers Prev 2013;22:1931-1943.

24 Beaber EF, Buist DS, Barlow WE, Malone KE, Reed SD, Li CI: Recent oral contraceptive use by formulation and breast cancer risk among women 20 to 49 years of age. Cancer Res 2014;74:4078-4089.

25 Obr AE, Edwards DP: The biology of progesterone receptor in the normal mammary gland and in breast cancer. Mol Cell Endocrinol 2012;357:4-17.

26 Gurney EP, Nachtigall MJ, Nachtigall LE, Naftolin F: The women's health initiative trial and related studies: 10 years later: a clinician's view. J Steroid Biochem Mol Biol 2014;142:4-11.

27 Imkampe AK, Bates T: Correlation of age at oral contraceptive pill start with age at breast cancer diagnosis. Breast J 2012;18:35-40.

28 Beral V, Bull D, Doll R, Peto R, Reeves G: Breast cancer and abortion: collaborative reanalysis of data from 53 epidemiological studies, including 83,000 women with breast cancer from 16 countries. Lancet 2004;363:1007-1016.

29 Wu JQ, Li YY, Ren JC, Zhao R, Zhou Y, Gao ES: Induced abortion and breast cancer: results from a population-based case control study in china. Asian Pac J Cancer Prev 2014;15:3635-3640.

30 Barry JA, Azizia MM, Hardiman PJ: Risk of endometrial, ovarian and breast cancer in women with polycystic ovary syndrome: a systematic review and meta-analysis. Hum Reprod Update 2014;20:748758.

31 Zreik TG, Mazloom A, Chen Y, Vannucci M, Pinnix CC, Fulton S, Hadziahmetovic M, Asmar N, Munkarah AR, Ayoub CM, Shihadeh F, Berjawi G, Hannoun A, Zalloua P, Wogan C, Dabaja B: Fertility drugs and the risk of breast cancer: a meta-analysis and review. Breast Cancer Res Treat 2010;124:13-26.
Brinton LA, Scoccia B, Moghissi KS, Westhoff CL, Niwa S, Ruggieri D, Trabert B, Lamb EJ: Longterm relationship of ovulation-stimulating drugs to breast cancer risk. Cancer Epidemiol Biomarkers Prev 2014;23:584-593.

33 Sergentanis TN, Diamantaras AA, Perlepe C, Kanavidis P, Skalkidou A, Petridou ET: IVF and breast cancer: a systematic review and meta-analysis. Hum Reprod Update 2014;20:106-123.

34 Horn J, Opdahl S, Engstrom MJ, Romundstad PR Tretli S, Haugen OA, Bofin AM, Vatten LJ, Asvold BO: Reproductive history and the risk of molecular breast cancer subtypes in a prospective study of Norwegian women. Cancer Causes Control 2014;25:881-889.

35 Kim JS, Kang EJ, Woo OH, Park KH, Woo SU, Yang DS, Kim AR, Lee JB, Kim YH, Kim JS, Seo $\mathrm{JH}$ : The relationship between preeclampsia, pregnancy-induced hypertension and maternal risk of breast cancer: a meta-analysis. Acta Oncol 2013;52. 1643-1648.

36 Kim HS, Woo OH, Park KH, Woo SU, Yang DS, Kim AR, Lee ES, Lee JB, Kim YH, Kim JS, Seo JH: The relationship between twin births and maternal risk of breast cancer: a meta-analysis. Breast Cancer Res Treat 2012;131:671-677.

37 Tong GX, Cheng J, Chai J, Geng QQ, Chen PL, Shen XR, Liang H, Wang DB: Association between gestational diabetes mellitus and subsequent risk of cancer: a systematic review of epidemiological studies. Asian Pac J Cancer Prev 2014;15:4265-4269.

38 Innes KE, Byers TE: First pregnancy characteristics and subsequent breast cancer risk among young women. Int J Cancer 2004;112:306-311.

39 Collaborative Group on Hormonal Factors in Breast Cancer: Breast cancer and breastfeeding: collaborative reanalysis of individual data from $47 \mathrm{epi}$ demiological studies in 30 countries, including 50,302 women with breast cancer and 96,973 women without the disease. Lancet 2002;360:187-195.

40 Faupel-Badger JM, Arcaro KF, Balkam JJ, Eliassen AH, Hassiotou F, Lebrilla CB, Michels KB, Palmer JR, Schedin P, Stuebe AM, Watson CJ, Sherman ME: Postpartum remodeling, lactation, and breast cancer risk: summary of a national cancer institute-sponsored workshop. J Natl Cancer Inst 2013;105:166-174.

41 Jäger S, Jacobs S, Kroger J, Fritsche A, Schienkiewitz A, Rubin D, Boeing H, Schulze MB: Breastfeeding and maternal risk of type 2 diabetes: a prospective study and meta-analysis. Diabetologia 2014;57:1355-1365.

42 Onitilo AA, Stankowski RV, Berg RL, Engel JM, Glurich I, Williams GM, Doi SA: Type 2 diabetes mellitus, glycemic control, and cancer risk. Eur J Cancer Prev 2014;23:134-140.

43 Xiong J, Piemontese M, Thostenson JD, Weinstein RS, Manolagas SC, O'Brien CA: Osteocytederived RANKL is a critical mediator of the increased bone resorption caused by dietary calcium deficiency. Bone 2014;66:146-154.

44 Palafox M, Ferrer I, Pellegrini P, Vila S, Hernandez-Ortega S, Urruticoechea A, Climent F, Soler MT, Munoz P, Vinals F, Tometsko M, Branstetter $\mathrm{D}$, Dougall WC, Gonzalez-Suarez E: RANK induces epithelial-mesenchymal transition and stemness in human mammary epithelial cells and promotes tumorigenesis and metastasis. Cancer Res 2012;72:2879-2888.

45 Hanf V, Kreienberg R: (Breast cancer: importance of environmental factors in its formation). Med Monatsschr Pharm 1998;21:265-274. 
-46 Kreuzer PE, Csanady GA, Baur C, Kessler W, Papke O, Greim H, Filser JG: 2,3,7,8-Tetrachlorodibenzo-p-dioxin (TCDD) and congeners in infants. A toxicokinetic model of human lifetime body burden by TCDD with special emphasis on its uptake by nutrition. Arch Toxicol 1997;71:383-400.

47 Wise LA, Titus-Ernstoff L: Exposure to breast milk in infancy and risk of adult breast cancer: more scientific data are needed. J Epidemiol Community Health 2010;64:745-746.

- 48 Wise LA, Titus-Ernstoff L, Newcomb PA, Trentham-Dietz A, Trichopoulos D, Hampton JM Egan KM: Exposure to breast milk in infancy and risk of breast cancer. Cancer Causes Control 2009; 20:1083-1090.

49 Innes KE, Byers TE: Smoking during pregnancy and breast cancer risk in very young women (United States). Cancer Causes Control 2001;12:179-185.
Silva Idos S, De Stavola B, McCormack V: Birth size and breast cancer risk: re-analysis of individual participant data from 32 studies. PLoS Med 2008; 5:e193.

51 Stephansson O, Granath F, Ekbom A, Michels KB: Risk of breast cancer among daughters of mothers with diabetes: a population-based cohort study. Breast Cancer Res 2010;12:R14.

52 Choi JY, Lee KM, Park SK, Noh DY, Ahn SH, Yoo KY, Kang D: Association of paternal age at birth and the risk of breast cancer in offspring: a case control study. BMC Cancer 2005;5:143.

53 Wilson KM, Willett WC, Michels KB: Mothers' pre-pregnancy BMI and weight gain during pregnancy and risk of breast cancer in daughters. Breast Cancer Res Treat 2011;130:273-279.
54 Yuen J, Ekbom A, Trichopoulos D, Hsieh CC, Adami HO: Season of birth and breast cancer risk in Sweden. Br J Cancer 1994;70:564-568.

55 Stocks P: Social status in relation to carcinoma of the breast. Schweiz Z Pathol Bakteriol 1955;18:706-717. 56 Brasky TM, Li Y, Jaworowicz DJ Jr, Potischman $\mathrm{N}$, Ambrosone CB, Hutson AD, Nie J, Shields PG, Trevisan M, Rudra CB, Edge SB, Freudenheim JL: Pregnancy-related characteristics and breast cancer risk. Cancer Causes Control 2013;24:1675-1685.

57 Bukowski R, Davis KE, Wilson PW: Delivery of a small for gestational age infant and greater maternal risk of ischemic heart disease. PloS One 2012 7:e33047. 